\title{
O "elemento feminino" na memória de Portugal: Murilo Mendes e Vieira da Silva
}

Maria Luiza Scher Pereira Universidade Federal de Juiz de Fora

\section{Uma questão inicial}

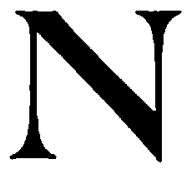

o artigo "Feminismo, experiencia y representación", Nelly Richard apresenta algumas questòes que têm animado o debate em torno do tema da "escritura feminina", dentre as quais destacamos a seguinte:

Podemos hablar - tan divisoriamente - de escritura masculina c femenina si el lenguage criativo, la textualidad poética, son espacios privilegiados de desplazamiento y transferencia del yo en los que se amplían y se remodelan incesantemente las fronteras de la subjetividad cultural, desbordando asi el realismo biográfico-sexual del sujeto 'hombre' o 'mujer'?'

Para responder a essá questão é preciso, segundo a crítica, rejeitar a coincidência tida como natural entre determinante biológica (ser mulher) e identidade cultural (escrever como mulher), para a partir dessa não coincidência compreender o feminino numa nova perspectiva crítica e teórica.

O feminino seria, numa rearticulação das políticas do signo, um "conceito-metáfora" segundo o qual se pode compreender a

'RICHARD, 1996. p. 740. 
expressão da marginalidade, da subalternidade e da dissidência. Desdobrando a percepção do feminino como a voz paradigmaticamente reprimida pela dominante de identidade social patriarcal, a autora afirma:

Ese 'femenino' no es un contenido de identidade ya formado (anterior y exterior a su representación verbal) sino la posición crítica que consiste en interrogar los mecanismos de constituición del sentido y de la identidad..."

Tais reflexões balizam a leitura que passamos a apresentar de alguns aspectos da obra de Murilo Mendes, na qual esse conceitometáfora poderá iluminar os modos de articulação entre os arquivos da tradição cultural, os procedimentos da memória, e a construção de um discurso que sugere novas perspectivas críticas e criativas.

\section{Masculino/feminino: o pinhal e a nave}

No livro Janelas Verdes, uma coleção de textos em prosa sobre cidades e artistas portugueses, Murilo Mendes destaca o famoso pinheiral plantado pelo Rei D. Dinis próximo à cidade de Leiria, como um dos seus cinco pontos fundamentais. Os outros quatro são o Castelo, o próprio rei Dom Dinis, Eça de Queirós, devido a $O$ crime do Padre Amaro, e Jaime Cortesão, seu sogro e amigo, na companhia de quem o poeta brasileiro visitou mais de uma vez a cidade. Mas é ao pinhal do rei que Murilo dedica a maior parte do texto sobre Leiria. Dele destacamos inicialmente o seguinte trecho:

Ninguém ignora que Dom Dinis ordenou o plantio do pinhal de Leiria, origem das futuras naves portuguesas; portanto nós brasileiros descendemos deste pinhal (...). Cada vez que o penetramos torna-se obrigatória, prevista mesmo, a referência às dinisianas "flores do verde pãio" (...)."

${ }^{2}$ RICHARD, 1996. p. 743-744.

1 MENDES, 1995. p. 1377. 
Fernando Pessoa, antes de Murilo, e José Saramago, depois dele, também nào escapam da associação de idéia entre o pinhal de Leiria e as naus da navegação. É famosa a estrofe do poema de Mensagem dedicado ao rei-poeta:

Na noite escreve um seu Cantar de Amigo

O plantador das naus a haver,

E ouve um silencio murmuro comsigo:

É rumor dos pinhaes que, como um trigo

De Imperio, ondulam sem se poder ver.

E no Viagem a Portıgal de Saramago a referência se repete:

E este é o pinhal de Leiria, o dos cantares do verde pino de D. Dinis, o das naus e caravelas das navegações, o frágil lenho que tào longe se aventurou.'

Nos três autores, temos a mesma referência a D. Dinis, poeta e plantador do pinhal que um século depois proveria de madeira o projeto competente de navegação da Escola de Sagres. Plantar o pinhal garantiu a ele participação talvez involuntária nessa história posterior e, muitos séculos mais à frente, valeu-lhe o belo verso de Fernando Pessoa: "o plantador das naus a haver".

Além de fazer circular as mesmas imagens, como se todos fossem citações uns dos outros, os textos de Pessoa, Saramago e Murilo Mendes têm outra coisa em comum: todos mencionam tanto o talento poético do rei quanto a sua ação prática, o poetar e o prover, o empreender e o cantar. Ao fazer isso, expõem de alguma forma a intrincada relaçào entre o processo histórico de construir a nação e os discursos que, ao mesmo tempo, mas não necessariamente na mesma intenção, se constroem.

O projeto das grandes navegações, que integra o amplo projeto da modernidade ocidental cujo sucesso e consolidação torna hegemônica a posição da Europa como centro, aparece nessas

\footnotetext{
4 PESSOA, 1975. p. 73.

'SARAMAGO, 1990. p. 157.
} 
representações poéticas da sua versão portuguesa associado metonimicamente ao pinhal, nome masculino, aqui referido como origem desse empreendimento também masculino (e também branco, cristão, adulto, isto é, europeu), que espalhará pelo resto do mundo, tornado entào periferia da Europa, o "trigo do império", para usar a expressão retirada do verso de Mensagem. ${ }^{6}$

Se pensamos que trigo pode remeter à idéia de semente e de alimento, acentua-se ainda mais a relação entre o pinhal e o elemento masculino, uma vez que cabe ao homem o papel de gerador (semente, sêmen) e provedor (alimento) dos filhos.

Plantado na verdade mais de um século antes do início das viagens portuguesas, para conter a erosão da costa litorânea, o pinhal pode ser por isso também associado ao que se enraiza, ao que se fixa como raiz entranhando-se no solo, tornando-se assim elemento de origem; da mesma forma se fixam, também por profundo enraizamento, os centramentos culturais e os mitos de identidade que se articulam na enunciação da narrativa da nação, e dão origem a outras falas e discursos identitários que continuamente a alimentam e a reafirmam.

Diferentemente as naves ou naus, nomes femininos, remetem ao desenraizado, ao que tendo sido arrancado do solo de origem perdeu suas raizes e, no caso, metamorfoseou-se, tornando-se as naus que se lançaram em errante aventura, embora fossem, como lembra Saramago, embarcaçōes caracterizadas pela fragilidadc, marca do feminino: "frágil lenho que tão longe se aventurou".

Assim, podemos perceber que a constituição da identidade da nação portuguesa e a história das viagens, residualmente presentes

" "El Logos de Occidente (consciencia, espiritu, historia, técnicas e ideologias) representaria (...) el dominio masculino de un proyecto civilizatorio que se há dedicado a reprimir sistemáticamente su outro lado más oscuro y salvaje (naturaleza, cuerpo, inconsciente, rito y mito) cuya naturaleza más viva se expresa en la oralidad femenina y popular: una oralidad que la máquina disciplinaria de Occidente há asimilado com violencia colonial a la cultura del libro y a su modelo de lo blanco, letrado y metropolitano." (RICHARD, 1996. p. 736-77). 
através dos elementos metonímicos pinhal e nave, atravessam os textos como rastros do passado no presente, que esses autores em três diferentes momentos do século XX e por circunstâncias diverisas, retomam.

Seguindo o rastro da tradição cultural pelo processo precário da memória, o resíduo se inclui em uma nova rede textual onde relações de sentido, também novas, se estabelecem.

Paul Ricoeur observa que o fenômeno do rastro, como o das ruínas, dos restos e dos documentos, por produzir "significância" em duas ordens temporais heterogêneas - passado e presente - deslocase do "historial para o intratemporal". ' Assim o viajante de Saramago no pinhal do rei-poeta aciona inicialmente o arquivo da memória nacional, mas, por efeito do deslocamento de que fala Ricoeur, continua a viagem em outra direção, inesperada:

(O viajante) vai indagar se nảo há caminho para Marinha Grande que lhe permita saborear por mais tempo a mata. Dizem-lhe que, haver, há, mas que o risco de perder-se é certo. Correu o risco, e se se perdeu não deu por isso. Sabe o que ganhou: (...) a mata é incomparável, (...) nenhuma mereceria mais ter, como habitantes, o povo pequenino dos gnomos, fadas e duendes. E (o viajante) está pronto a apostar que um súbito remexer de folhas que ali se viu foi obra de um esperto anãozinho de barrete vermelho."

Observe-se que perder-se no pinhal é também embaralhar, no relato da viagem do presente, as referências fixas da história pela superposição de um outro arquivo, o da memória infantil, que guarda resíduos do mundo mágico dos contos de fadas, libertário em relação ao mundo adulto do grande empreendimento da história. Assim, o texto do viajante é descontínuo: narrativas diversas se entremalham, quando o lúdico desloca o histórico e as memórias se misturam.

\footnotetext{
'RICOEUR, 1997. p. 196-209.

${ }^{8}$ RICOEUR, 1997. p. 157.
} 
Também em Murilo Mendes as cristalizações cedem a novas fulgurações de sentido. Como se vê no trecho citado, Murilo também se inscreve no grande texto da história quando afirma que nós, brasileiros, descendemos do pinhal, inserindo, ainda que de forma bem-humorada, a nossa origem na ação masculina do empreendimento moderno europeu. Contudo, após incluir-se, e a nós brasileiros, na narrativa da viagem portuguesa pela irreverente simplificação e pela dedução só aparentemente lógica ("portanto, nós brasileiros descendemos desse pinhal"), o poeta passa a ocuparse daquilo que sua viagem, particular e presente, desencadeia:

Nesta visita rodeia-me uma sensaçào que considerava absurda; mas finalmente vi-a partilhada por um escritor da força de Raul Brandăo: "a verde solidåo dos pinheirais, que associo sempre à idéia do mar largo." Com efeito acho que o pinheiro, manso ou bravo, ondula. Assim, incluo tambêm um elemento feminino, onda; $e$ sem o elemento feminino quem poderia suportar o peso dos textos, a começar pelo poeta??

Embora Murilo cite Raul Brandão e não Fernando Pessoa, é curioso observar que a associação entre o movimento dos pinheiros e a ondulação do mar que leva ao elemento feminino, onda, já está nos versos de Mensagem: " $E$ o rumor dos pinhaes que como trigo de Império ondulam sem se poder ver".

Esse processo de apreensão da experiência subjetiva e particular de Murilo Mendes é semelhante ao de Saramago, que julgou ver gnomos de barrete vermelho surgirem no pinhal, logo transformado de lugar solene em espaço mágico. Operando pela associaçào de imagens visuais a inesperadas relações de sentido, $\mathrm{e}$ produzindo o efeito de "sensação absurda", a memória de Murilo Mendes também desloca as referências cristalizadas pela grande história das navegações.

Antecipando a proposta de Ítalo Calvino para o próximo milênio, ao viajar pela grande narrativa nação moderna (também a

'MENDES, 1995. p. 1377. Grifos nossos. 
brasileira), Murilo conclama a leveza desse elemento feminino contra o "peso dos textos", contra sua solidez insuportável. Se o viajante de Saramago insere o infantil, pela via do conto de fadas, Murilo inclui o feminino nessa história masculina do projeto moderno das viagens.

Nesse sentido, tanto os gnomos dos contos de fadas de Saramago quanto a onda que traduz o elemento feminino de Murilo se equivalem no âmbito daquele conceito-metáfora de que fala Nelly Richard, jã que ambos os elementos operam como um vetor de desestabilização da solenidade da história nacional.

\section{O elemento feminino e a presença de Vieira da Silva}

Se, seguindo a pista do poeta, tomamos o elemento onda como metáfora do feminino que perturba a história masculina da nação portuguesa moderna, podemos ampliar nossa leitura observando dois outros elementos associados, na obra de Murilo Mendes, tanto à onda como à própria mulher - movimento e transformação. Em O discipulo de Emaüs, de 1945, dedicado a Maria da Saudade Cortesão, com quem viria a se casar dois anos depois, Murilo afirma em tom de aforisma: 'A mulher determina continuamente no mundo uma transformação maior do que todas as revoluções". "'

No livro As Metamorfoses, considerado por Luciana StegagnoPicchio "livro central da produção poética de $\mathrm{MM}^{\text {", " a articulação }}$ de sentido entre todos esses elementos - onda, mulher, movimento e transformação - pode ser encontrada em vários momentos. Cito alguns versos, seguidos dos nomes dos poemas, todos desse livro:

Sentado no horizonte

Contemplo as casa fugirem.

$A$ onda que vai e vem

Comunica-se com a estrela... (Alcance, p. 341)

"MENDES, 1995. p. 886.

"PICCHIO, 1995. p. 1653. 
Debruçado sobre a noite

Refiz o reino das fadas

(...)

Contemplo ao longe a fileira

Das amadas que semeei,

E o rastro de Deus nas ondas. (A extensão dos tempos, p. 344)

Mulher

Ora opaca ora translúcida

Submarina ou vegetal

Assume todas as formas,

Desposas o movimento.

(...)

Tu és na verdade, mulher,

Construçăo e destruição. (Mulher, p. 350)

Na dignidade da onda

Puseste os pés de poesia

Que as fadas tornearam em séculos. (A criação feminina, p. 363)

Entendemos que para Murilo Mendes a idéia do feminino, ligada a movimento e metamorfose, resulta também na associação entre esse elemento e a própria construção da poesia, compreendida pelo poeta como alternativa para o mundo real, histórico, embora seja, ao mesmo tempo, profundamente ligada a ele.

Isso seria particularmente perceptivel nesse livro, escrito entre 1938 e 1941, sendo deste ano todos os poemas do "Livro Segundo", intitulado "O véu do tempo", entre os quais destacamos os fragmentos citados acima. Nele, a metamorfose operada pela e na construção da poesia parece constituir-se como única alternativa de esperança no futuro, diante da dura realidade presente do mundo em guerra. Em poemas como "A bela e a fera" e "Orfeu", dos quais extraímos, respectivamente, as estrofes abaixo, podemos observar isso:

O mundo inteiro se tinge

Do sangue do Minotauro,

Até que a branca Poesia

Lhe mostre o dedo mindinho. (p. 347) 
Ajudo a construir

A Poesia futura,

Mesmo apesar dos fuzis. (p. 342)

É nesse mesmo "Livro Segundo" de As metamorfoses que encontramos na obra de Murilo Mendes a primeira referência à pintora portuguesa Maria Helena Vieira da Silva, que com o marido, o húngaro e também pintor Arpad Szenes, refugiou-se no Brasil entre 1940 e 1947, fugindo tanto da guerra que os impedia de ficar em Paris, quanto do salazarismo que não lhes permitia ir para Lisboa. No poema que tem como título o seu nome completo, ela é referida como "bicho que habita na escadaria do século, entre o sibilar das granadas, e a saudade dos minuetos".

Sendo portadora, ao mesmo tempo, de determinados elementos e de seus contrírios, "diurno e noturno, longo e breve, másculo e feminino", Vieira é também chamada por Murilo de "onda e serpente, água metálica c chama rastreante", recuperando-se assim a associação já vista entre o elemento feminino onda e a idéia de movimento e transformaçào, que se traduz também na possibilidade da poesia, e da arte. Nos versos a seguir Murilo fala do modo como Vieira da Silva constrói sua pintura:

\section{Bicho nervoso}

Minucioso

Tece uma trama há mil anos

Que se transforma com a luz.

Em contraponto às formas

Da cidade organizada. ${ }^{12}$

A idéia de que a arte de Vieira é "a trama que se transforma" e de que contrapõe-se "às formas da cidade organizada" expressa aquela relaçào entre a criação artística (nesse caso, tanto a pintura de Vieira quanto a poesia de Murilo) e os processos de deslocamento e de rearticulação de sentido, que esgarçam o tecido cerrado dos discursos hegemônicos.

${ }^{12}$ MENDES, 1995. p. 351. 
Voltando ao Janelas Verdes, o livro de Murilo sobre Portugal, encontramos no texto sobre Lisboa, outra referência a Vieira e às formas da cidade organizada, significativas à nossa leitura:

Os homens tudo fazem para deformar a fisionomia de Lisboa. Destroem as casas "de várias cores", (...) levantam em seu lugar edifícios de gosto discutivel...

Vendo-a golpeada de todos os lados o gnomo de Lisboa refugia-se em certos quadros de Vieira da Silva. (...) podemos habitar livremente esses quadros onde nào há rastro de polícia, nem crueldade, nem mistificação, nem demagogia, nem miséria; sim uma Lisboa imaginária, suspensa no espaço e no tempo, adversa, mesmo, à original: attre. Essa Lisboa reconcilia-se com a tonalidade azul e com a palavra azul...13

A transformação física de Lisboa continua a escrever a história do empreendimento masculino e adulto representado nos edifícios que se levantam, agora nos termos do contemporâneo progresso urbano que desfigura as versões anteriores da cidade, esse ícone da modernidade européia e ocidental. Dissonantes, reencontramos tanto nos quadros de Vieira e no texto de Murilo, como antes no de Saramago, o gnomo, o feminino (o azul não lembraria a cor da onda?), e a arte que se constroem como alteridade.

É provável que Murilo se refira nessa passagem ao quadro Lisbonne bleue, de 1942, do período do exílio de Vieira no Brasil. Em outro quadro, o Lisbonne du souvenir, de 1940, no mesmo contexto referido por Murilo nas expressōes polícia, crueldade, demagogia, Vieira volta ao traço do desenho infantil, recriando Lisboa pela "poética" que, no texto de Janelas Verdes intitulado Vieira da Silva, e dedicado "à própria", Murilo define como "uma poética baseada na arquitetura da memória; um conto de fadas da cidade moderna". ${ }^{14}$

\footnotetext{
${ }^{33}$ MENDES, 1995. p. 1410.

"MENDES, 1995. p. 1442.
} 
Em ambos os quadros podemos encontrar uma Lisboa autre, que pelos elementos da cor $\mathrm{e}$ do tema, contrastantes com o estado do mundo em guerra, esse outro negócio de homens, expressa a transgressão criativa dessa pintora exilada e estranha. 15

A instigante contradição entre "conto de fadas" e "cidade moderna" na condensaçio poética do texto de Murilo ilumina a reflexão, motivada pelo rearranjo de signos, formas, cores e palavras, sobre o funcionamento do elemento feminino no processo de construção da linguagem da arte como alternativa aos discursos hegemônicos e totalizadores.

Da aproximação entre Murilo Mendes e Vieira da Silva voltamos, para concluir, à questão inicial sobre a linha divisória entre escritura masculina e escritura feminina. Para Nelly Richard a ressemantização do termo 'feminino', que pode passar a ser lido como alteridade, resulta de "la dinámica de los signos" no âmbito de uma nova perspectiva teórica e crítica. E completa: "la ruptura de las significaciones monológicas puede ser comparticla por autores masculinos si su práctica del discurso busca también fisurar el molde del concepto". ${ }^{16}$

Confrontando significaçōes monológicas presentes na grande narrativa da tradição portuguesa, Murilo Mendes e Vieira da Silva, constroem seu texto critica e criativamente pelo processo transgressivo que opera inclusive através do elemento feminino, como também fizeram, cada um à sua maneira, Fernando Pessoa e José Saramago.

1s Também no texto Lisbona, de Jpotesi, Murilo Mendes constrói semelhante representaçào da cidade de lisboa pela leitura dos quadros de Vieira da Silva: Un corteo di finestre gialle blu / s'affaccia sul fiume mare / stanco di sostenere navigazioni / dall'epoca dei fenici. (...) posso toccare un'autra Lisbona / nei quadri di Vieira da Silva / dove non entrano / la prigione, la paura, la censura. / L'occhio vi ritrova la pace / troncata dai dittatori-poliziotti / e dai poliziotti-dittatori. (MENDES, 1995. p. 1539)

16 RICHARD, 1996. p. 741. 


\section{Referências Bibliográficas}

MENDES, Murilo. Poesia completa e prasa. Org. Luciana Stegagno-Picchio. Rio de Janeiro: Nova Aguilar, 1995.

PESSOA, Fernando. Obra poética. Org. Maria Aliete Galhoz. Rio de Janeiro, Nova Aguilar, 1975.

PICCHIO, Luciana Stegagno. Vida-poesia de Murilo Mendes. In: MENDES, Murilo. Poesia completa e prosa. Org. Luciana Stegagno-Picchio. Rio de Janeiro: Nova Aguilar, 1995

RICHARD, Nelly. Feminismo, experiencia y representación. Revista Iberoamericana, University of Pittsburgh, v. LXII, n. 176-177, p. 733-744, Julio-Diciembre 1996.

RICOEUR, Paul. Arquivos, documento, rastro. Tempo e narrativa. Tomo III. Trad. Roberto L. Ferreira. Campinas, SP: Papirus, 1997.

SARAMAGO, José. Viagem a Portugal. Rio de Janeiro: Cia. das Letras, 1990. Juiz de Fora, agosto de 2001.

\section{Resumo}

Este trabalho apresenta um aspecto da pesquisa sobre a presença de traços do arquivo cultural português na obra de Murilo Mendes. Pretende-se observar como o elemento feminino, presente na poesia de Murilo, funciona na representaçào de Portugal, no texto memória/relato de viagem do livro Janelas Verdes. A partir disso, observa-se ainda como Lisboa é representada por Vieira da Silva, num semelhante processo de acionamento da memória, em quadros produzidos no seu periodo de exílio no Rio de Janeiro.

\section{Abstract}

This paper discusses an aspect of the research into the presence of certain features of Portuguese cultural archives in the work of Murilo Mendes. Our aim is to examine how the female element, present in Murilo's poetry, works out in the representation of Portugal, in the text from the book Janelas Verdes, considered as both memoirs and tmvel accounts. From that perspective, it is also observed how Lisbon is represented, in a similar process of activating memory, in pictures produced by Vieira da Silva during his exile in Rio de Janeiro. 